ORIGINAL ARTICLE | ISSN (0): 2582 - 631X DOI: 10.47857/irjms.2020.v01i04.020

\title{
Banjara Lifestyle and Community
}

\author{
Mahanthy Dhanavath
}

Department of Metallurgical and materials engineering, IIT Patna, Bihar, India.

\begin{abstract}
The Lambadi people (also known as Banjara, Gormati, Vanjara and Gor). The community described as perambulant people from north west of India from Mewar region now the location is Rajasthan. There are one of the Scheduled Tribes communities spread out mostly in southern part of India like Karnataka, Andhra Pradesh and Telangana and some parts of Northern India.

British Colonial Authorities has passed the Act of 1871 under the preview of Criminal Tribes in 19th century, which made them to give up their classical occupations. Due to the impact some of them resolve into farming and others gone back to the forest. This led to some of them settling down as farmers and others are driven into the forest.
\end{abstract}

Keywords: Banjara Dance, Food, Culture, Tattoos and Festival.

\section{INTRODUCTION}

The Banjaras speak Gor Boli also called Lambadi. It belongs to the Indo-Aryan Group of Languages. Lambadi has no script. Most of the banjara speak today bilingual or multilingual adopting the predominant language of their surroundings.

Banjara is made of various group found throughout India and most of them are found in Telangana, Andhra Pradesh and Karnataka states in South India. They tend to live in small isolated groups called thanda. Now many people are engaged in farming and breeding cattle. Due to their isolation, most are not well educated and are very poor in some instances. Compared to other groups in the area, the Lambadi are tall with fair complexion and classical Nordic features.

They are largest scheduled tribes of India and have originally come from Rajasthan. They were engaged in business of collecting, carrying and supplying goods to the travelling and invading armies during pre-colonial period.
During the peace time they were transporting the goods to the nearby markets. The chief mode of transportation was supported by cattle (1). Mr. G. A. Grierson writes that," the Banjara are the wellknown tribe of carriers who are found all over Western and Southern India. The language that is spoken by Lambada is known as "Gor Boli" or Lambadi (2).

The nomadic communities like Lambadas have been historically on constant move. According to a report submitted by the All India Banjara study team, it is learnt that, the banjara are known by at least 26 different names (3) and have at least 17 subgroups (4) across various states of India (5). The lambadi also claim themselves as kshyatriya tribe. These tendencies are more visible especially, among the lambadi of South India (6). In the addition they are known for believing in several blind faiths (7). This manuscript is to explore (i) To know the origin and Historical Background of Banjara and (ii) To know their Banjara community and its cultural heritage.

*Address of Correspondence: 8-43/7/40, Balaji hills colony, Uppal, Hyderabad, Telangana - 500039, India.

E-mail- mahanthydhanavath@gmail.com

(Received 17 September 2020; revised 29 September 2020; accepted 03 October 2020) 


\section{CULTURE}

Banjara Culture varies from others who living in the society. According to the research the costume and personal adornments of the Lambadi women. Married women are distinguished from the unmarried in that they wear their bangles between the elbow and shoulder. In the Research Generally, it is being observed that the weight of the decorated garments, skirt, blouse and scarf alone can weigh
2 to 5 kilos, with the bracelets, anklets, waist, chain necklace, ear rings and others effects weighing some more.

Generally much of the jewellery is composed of myriad weighty elements. Hollow lead balls that make rhythmic tinkle while walking are used. The following images will provide us some visual information about the traditional jewellery of the Banjara (Figure 1).

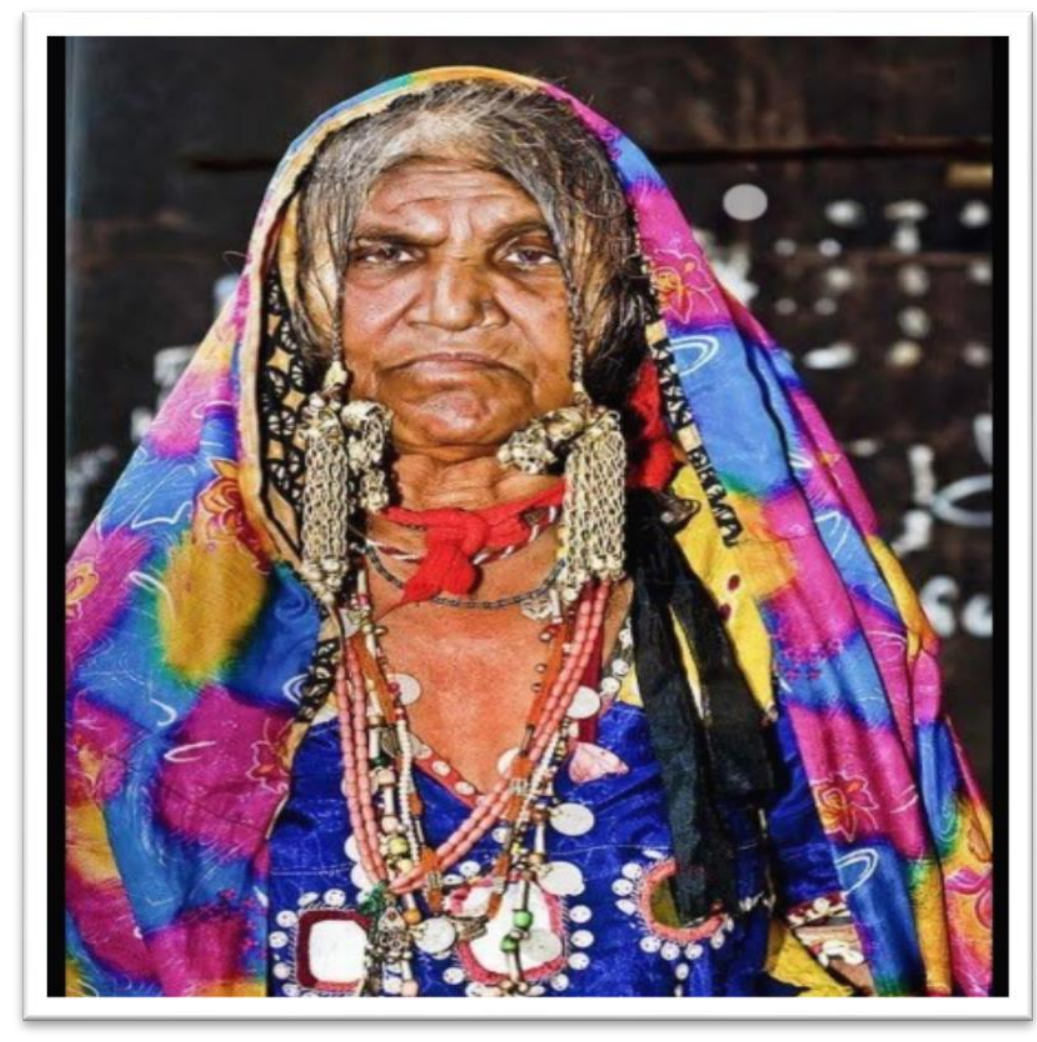

Figure 1: Lambadi Women (8)

Along with jewellery, bangles also play a distinct role in banjara costume. Textiles of the banjara describe with wonder the number of ivory bangles worn by banjara women. "There arms, indeed are so encased with ivory that if would be no easy matter to clean them (9).

The women wear a peculiar dress, consisting of a lunga or gown of stout coarse print phetiya (the skirt), a tartan petticoat kanchali (blouse) and a mantle often elaborately embroidered, which also covers the head and upper part of the body. The arms are profusely covered with trinkets and rings made of bones, brass and other rude materials. Baliya (bangles), Karautiya (anklet), Hassli (the necklace made of coins), Bhuriya (nose ring), kolda (leg ankle rings), Gargi (Figure 2).

Whereas the men's dress consists of a white or red turban, and a dhoti on the bottom and kurta on the top (Figure 3). 


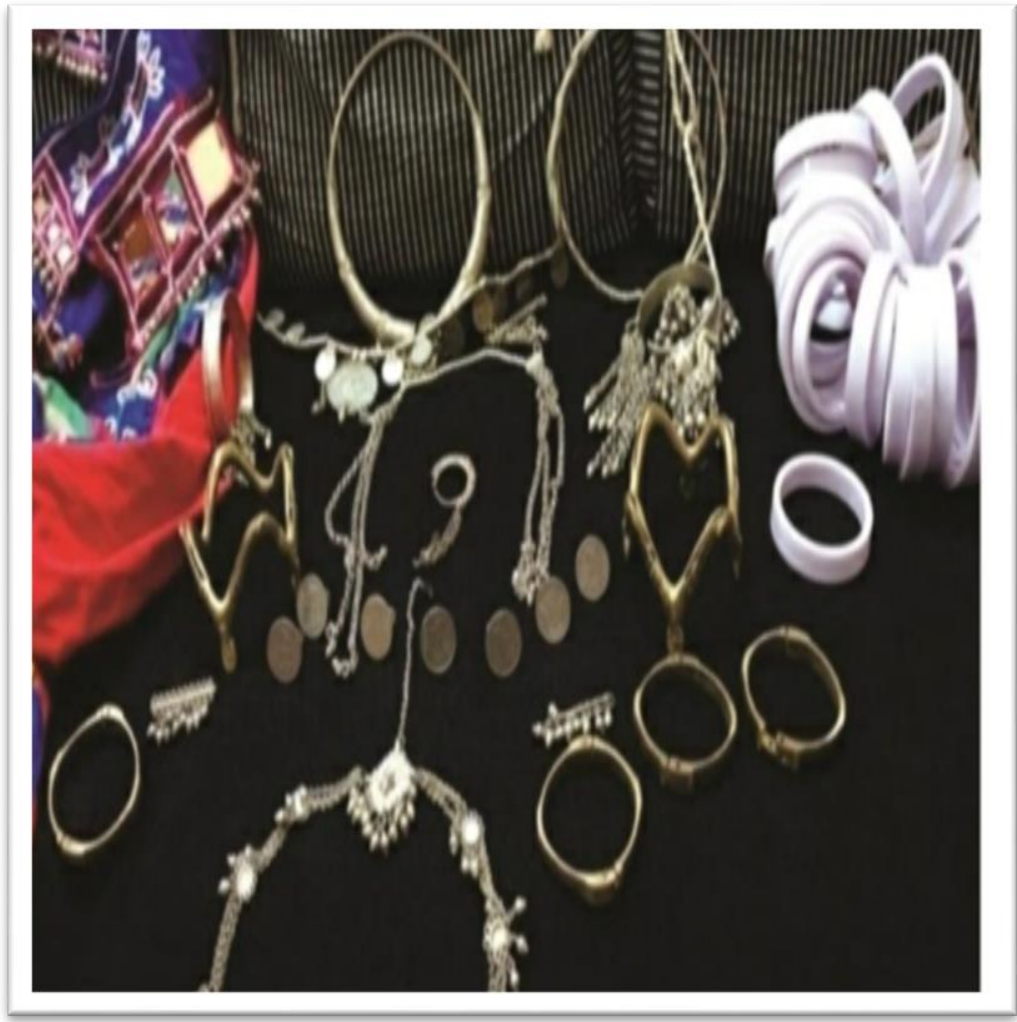

Figure 2: Banjara's Costume and Ornaments (10)

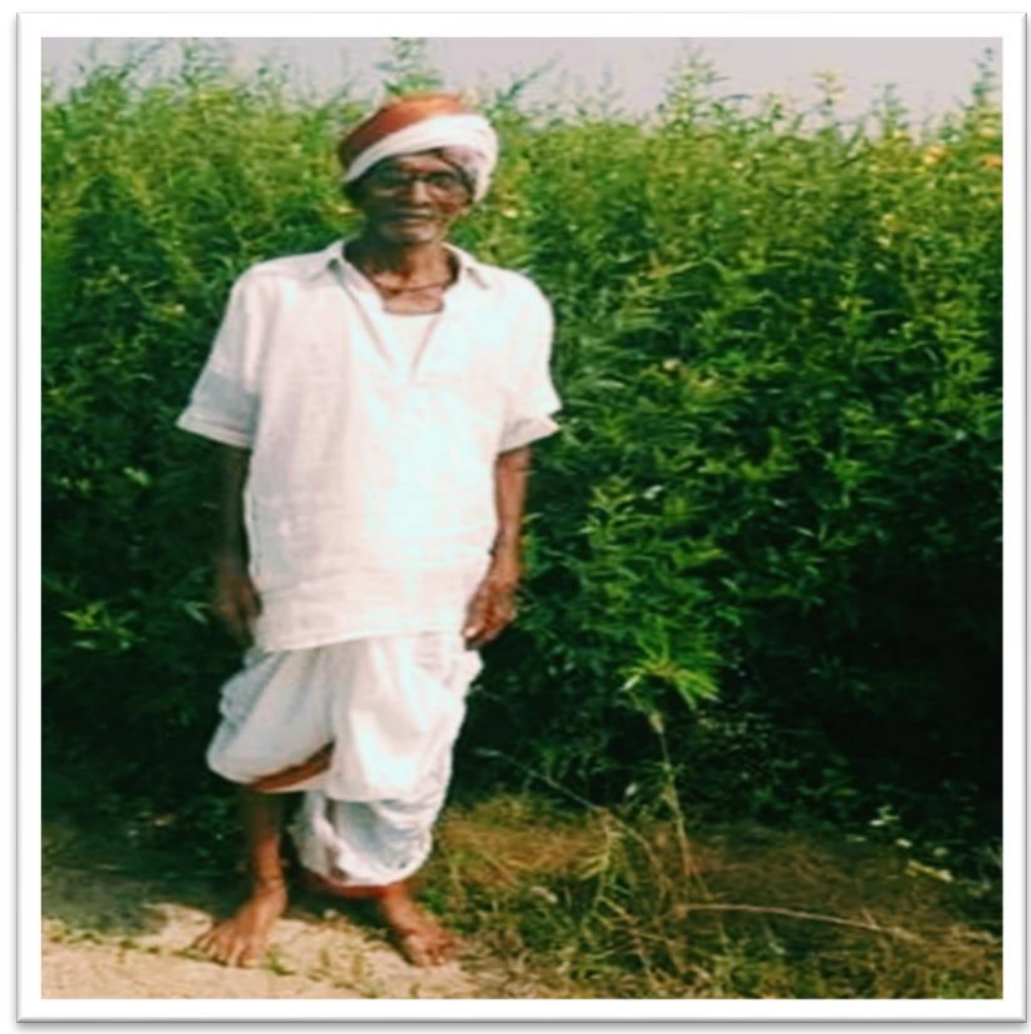

Figure 3: Lambadi Man with Traditional Dress 


\section{COMMUNITY}

Banjara people live in "Tanda" keeping a distance from non-banjara people. The community was held by the community leader "Nayak"(head of the community) led the community both in matters of socio-political and religious life. Tanda Jury Board is headed by the Nayak and wise people of the village who gives valuable suggestions to the Nayak for wellbeing of the thanda. There was no practice of going out to register cases in police station or trail in all courts. Tanda jury saves money and reputation.

\section{FOOD}

Traditional food of banjara people were Daliya (mixed cereal), bati (roti), saloi (made from goat or sheep and intestine) and Ghuggari (boiled red grams). 'patali bati' is made from ragi or bajra and they eat with chicken curry or green leafy vegetables.

\section{TATTOOING}

Tattoos are very common in banjara community. Like the banjara costume, Tattoo also express their personal style, identity and family connect. There is a superstitious belief is involved to avoid illness and misfortune. Like their decoration on costume with mirrors, tattoos are also both decorative for beauty and as protection from ill health or recognition. This tattooing form a significant aspect of the Banjara people (Figure 4).

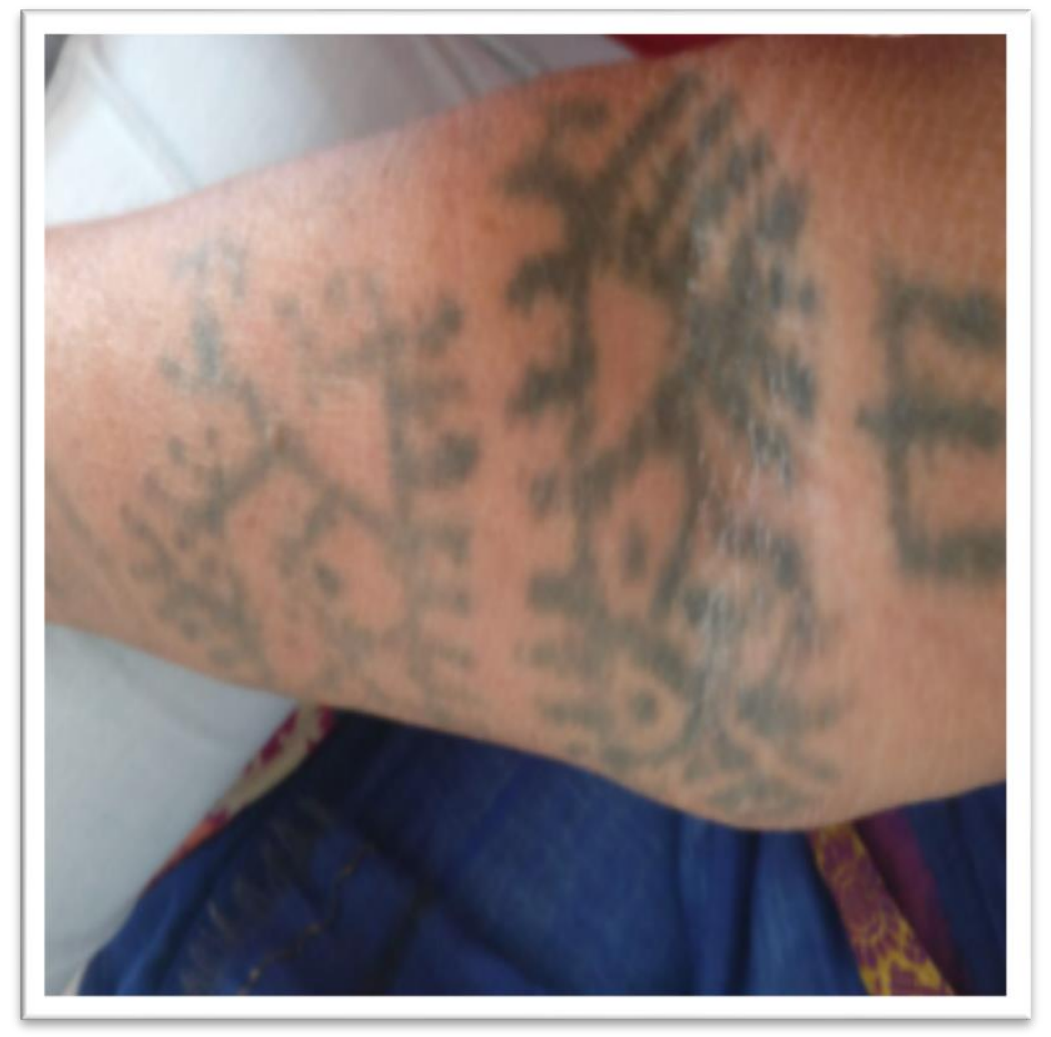

Figure 4: Woman with Banjara Tatoo

\section{FESTIVALS}

Banjara people celebrate the festival of teej during Shravanam (in the month of august). In this festival young unmarried Banjara girls pray for a good groom. They sow seeds in bamboo basket and water it three times a day for nine days and girls sing and dance and if sprouts grow "thick and high". It is considered as a good omen. Banjara celebrate the Hindu festivals Dussehra, Diwali, Ugadi, Holi and Ganesh Chaturthi. During Holi woman go around village, perform kolata and both men and woman gather around the fire and have great fun and enjoy in celebration (Figure 5) (11). 


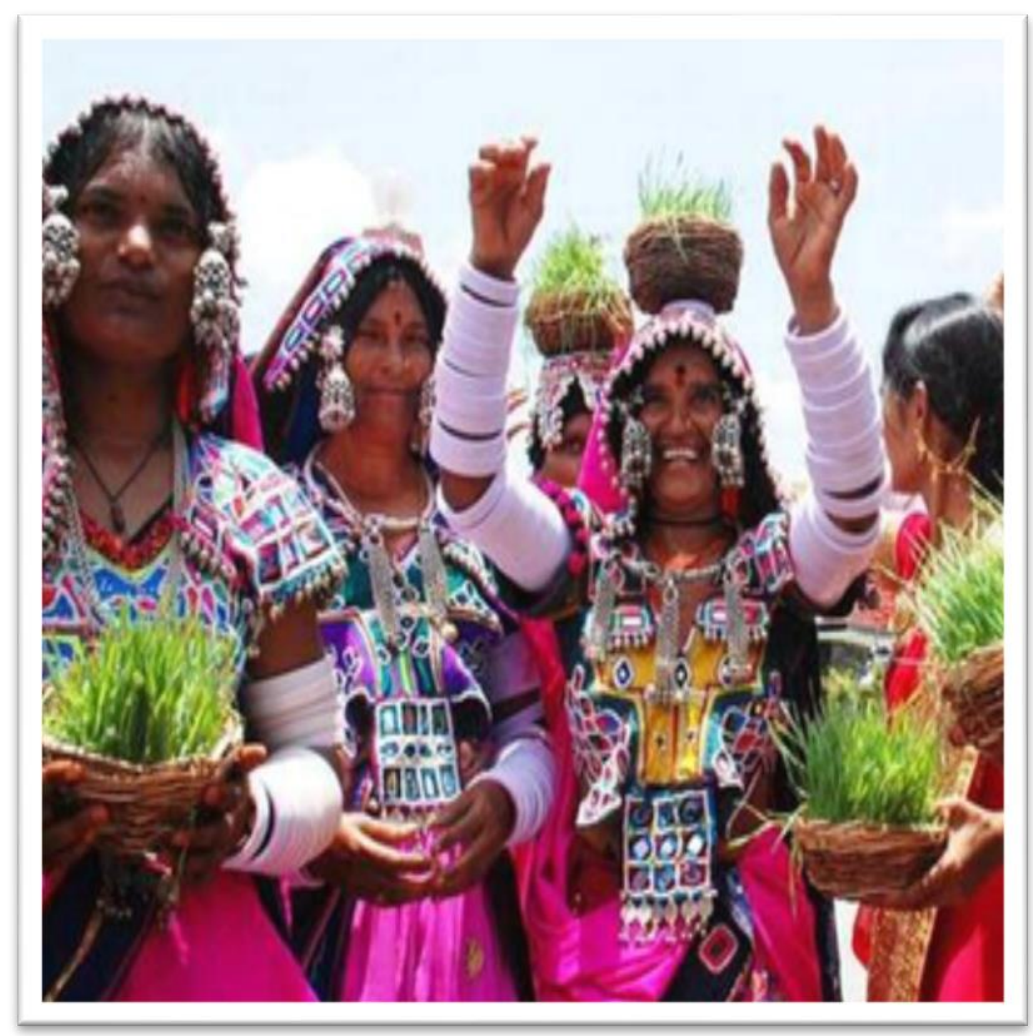

Figure 5: Banjara Teej Festival (12)

\section{DANCE}

Folk songs were sung by both men and women (14). Precession, bronze plates and cymbals were the musical instruments. Both men and women dance to the tune of drum. Fire dance and Chari are the traditional dance forms of banjara people (15).

\section{RELIGION}

They profess faith in Hinduism. They worship pilgrims as Balaji, Jagdamba Devi, Bhavani of Tuljapur, Hanuman, Renuka Mata. They also hold Guru Nanak in great respect. Sevalal is the important saint of Banjara. Truthfulness, musician, warrior and who fought for superstition. The colonial British administration also quotes his stories in 19th century.

\section{POPULATION GROWTH}

After Independence, the community was identified in the 1950s, but were (and continue to be) listed under the Habitual Offenders Act, 1952. They slowly became daily wage workers on farms and construction sites.

After 2008, the Vanjara community has called as Schedule Tribe (ST) in parts of India in Rajasthan, Andhra Pradesh, Telangana, Orissa, Chattisgarh, Karnataka, Delhi and Punjab and other backward class in Gujarat, Harayana, Maharastra, Madhya Pradesh and parts of India. Due to British Colonial Authorities brought the community under the preview of the Criminal Tribes Act of 1871. Most of them become traders and move away from place to place and now some have settled as farmers and others were driven into the forest and migrated and divided in all parts of the country and which forced them to give up their traditional occupation.

According to her survey the total population of banjara in India 2020 is $12,10,00,000$ and statistics proven that (Figure 6 and 7). 


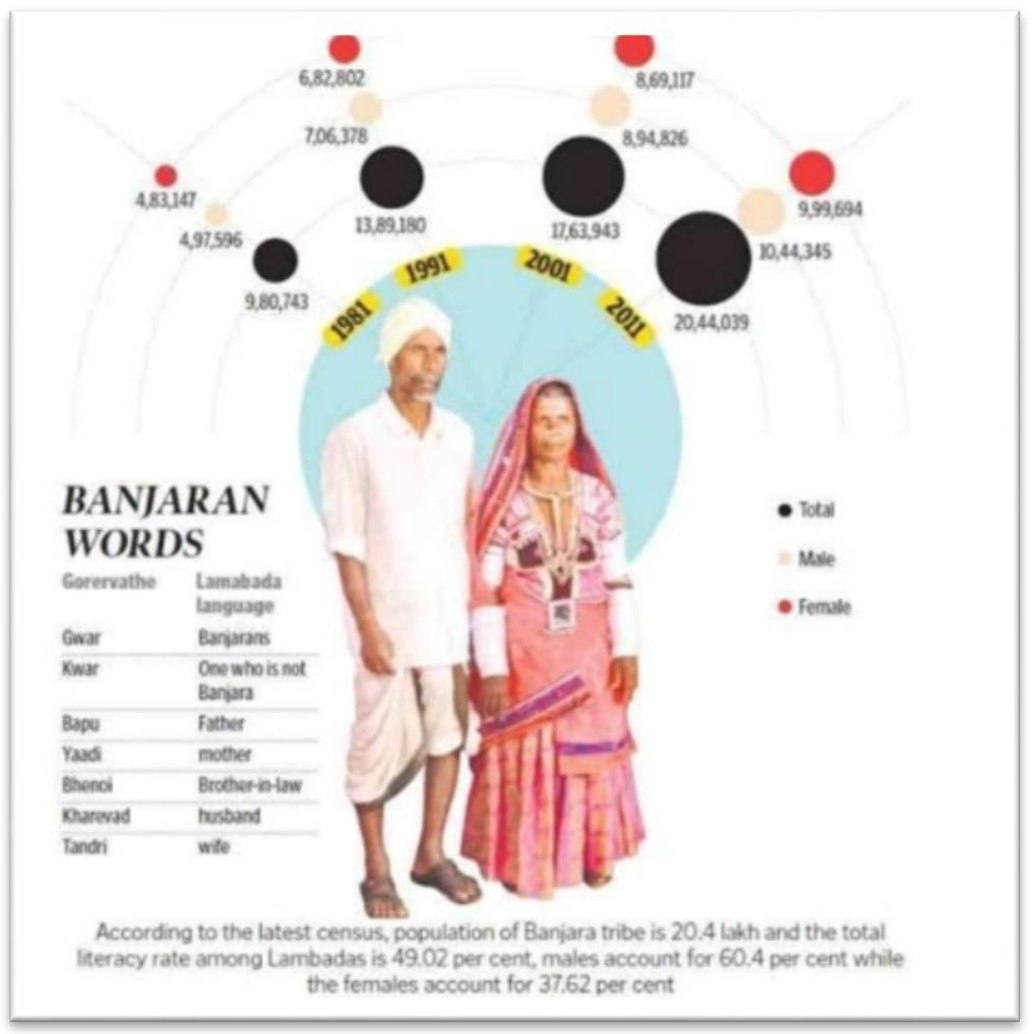

Figure 6: Banjara Population Chart and Enduring Tribe (13)

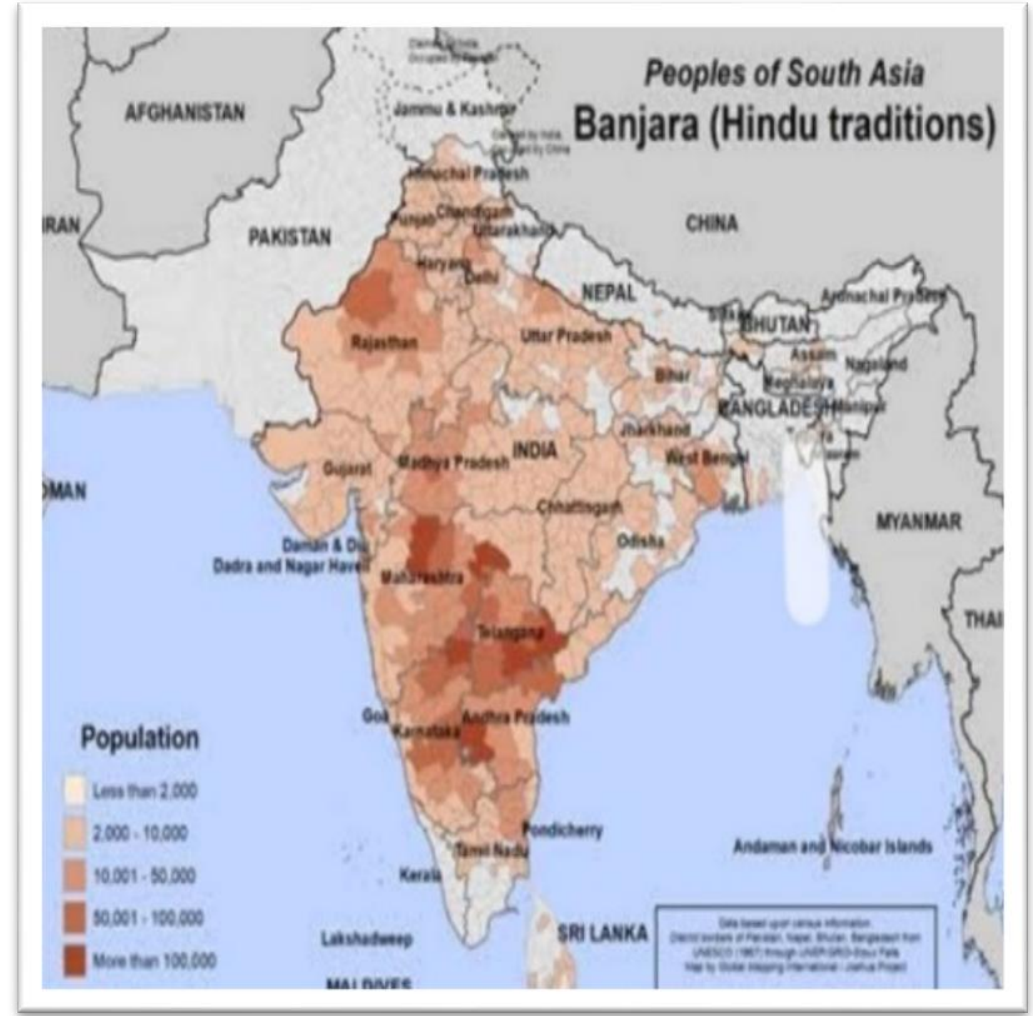

Figure 7: People of Banjara Hindu Tradition (16) 


\section{DISCUSSION AND CONCLUSION}

Banjara were one of the ancient nomadic tribes of India which possessed a peculiar habitation, history, culture, religious and social-practices, festivals, language, dress, governing system. It is limited by various factors of physical environment, technology, ecology, their own history by the colonial rule(17). There is a need of reforms taken by the educated people of the community, because the power of illiterate lambada's is just imitating the Hindu practices adopted by them (18). Many tribal characteristics, culture and social practices have gone under tremendous change. Most of the Banjara Community people migrated to the city due to severe poverty expecting a better lifestyle and proper living system. However this impacted their tribal life and Cultural practices as they got introduced to the modern culture and a different language. A big ratio of them got so used to the city lifestyle that it became very difficult to move beyond it.

\section{CONFLICT OF INTEREST}

The authors have no conflict of interest regarding the research content of the article. This journal is not to hurt the sentiments of any person.

\section{FUNDING}

No Funding.

\section{REFERENCES}

1. Certain communities have been recognised constitutionally as Scheduled Tribe and State Affirmative Action has been extended communities in India.
2. G.A.Grierson Survey of India,(1907):in "Castes and Tribes of Southern India',vol-4,Madras,Govt Press(Madras,1909); 208.

3. D.B.Naik: The Art and Literature of Banjara Lambadi's; Abhinav Publication, (New Delhi, 2000).

4. 26 Different languages of banjaras are: Banjari, Vanjari, Banjare, Binjari, Lamban, Lambadi, Laban, labhan, labhanis, Baladia, Sugali, Gwar.

5. 7 sub-groups of the banjaras: Gor, Mathura, Dhadi, Sanar, Navi, Dhadia, Shingadya, Maru, Bamania, Bagora, Digora, or Gigora, Charan, Badi, Bajigar, Jogi or Bharava, Rohidas and Dhan-Kute.

6. The Art and Literature of Banjara Lambadi.

7. Number of bhagats of some goddesses whom ignorant Banjaras consult them as gods or goddesses are supposed to speak through them.

8. Anoop Negi. The ancient nomads of India- a Lambadi women. Flickr.com . June 27, 2009. (https://www.flickr.com/photos/ezee123/36709849 25/in/photostream/)

9. Lambadi embroidery gets GI tag.

10. Collections from professor Surya Dhanujya.

11. Naik (2000).The Art and Literature of Banjara Lambanis: A Socio-cultural Study. New Delhi 2000; p.132. ISBN 9788170173649.

12. Pradeep. Teej Festival. Thehindu.com. August 6,2017.

( https://images.app.goo.gl/cEhQf7QHBNAfmMEC9)

13. Nikisha Uddagiri. The resilient and enduring tribe of banjaras. Telanganatoday.com. May 6th,2018.

(https://images.app.goo.gl/p6VcoS5ykYXvz7NC8).

14. Sing, People of India, Vol.2,125.

15. First the banjara dance origin is from Nalgonda.

16. People Group Collection: Omid. Banjara(Hindu Traditions) in India. joshuaproject.net. 2020.

( https://images.app.goo.gl/2J1rsHz79XeqzK9a8).

17. Banjara tribe refuses to snap tie with their culture.

18. Bhangya Bhukya; The Lambadas under the rule of the Nizams. Hyderabad. P.233.January 12010. 